\title{
Association between Metabolic Syndrome and Alcohol Consumption: A Cross-sectional Study
}

\author{
Kochakorn Trisrivirat, M.D., Kanokporn Pinyopornpanish, M.D., \\ Wichuda Jiraporncharoen, M.D., M.Sc., Lalita Chutarattanakul, M.D., \\ Chaisiri Angkurawaranon, M.D., Ph.D.
}

Department of Family Medicine, Faculty of Medicine, Chiang Mai University, Mueang, Chiang Mai 50200, Thailand. Received 8 November 2019 • Revised 11 June 2020 • Accepted 22 June 2020 • Published online 10 November 2020

\begin{abstract}
:
Objective: To determine the association between metabolic syndrome and alcohol consumption, including drinking patterns and risk of harm.

Materials and Methods: A cross-sectional study was conducted on 400 participants recruited from the Outpatient Unit of the Family Medicine Department, Faculty of Medicine, Chiang Mai University. Physical examination and blood tests were carried out to evaluate the presence of metabolic syndrome. The drinking patterns were stratified into four levels, which were abstinence, occasional drinking, light-moderate drinking, and heavy drinking (>40 gm/day). The Alcohol Use Disorders Identification Test was used to evaluate the risk of harm from alcohol consumption.
\end{abstract}

Results: The percentage of current drinkers was $27.3 \%$, and most of them were men (87.2\%). Waist circumference, triglyceride levels, and diastolic blood pressure were significantly higher among those with a heavy drinking habit and harmful alcohol use/dependence. High density lipoprotein cholesterol (HDL-C) showed different results. A J-shaped association was found between HDL-C and drinking pattern, but an inverse relationship was indicated with the risk of harm. Metabolic syndrome was found to be significantly associated with heavy drinking (OR=4.4, 95\% Confidence Interval (Cl) 1.2-15.6, p-value 0.021) and the harmful use/dependent categories (OR=5.0, 95\% Cl 1.1-23.1, p-value 0.039). Conclusion: The results suggest that alcohol drinking tends to be associated with an increased risk of metabolic syndrome. This condition should be screened regularly especially in those with heavy drinking or at-risk drinking habits.

Keywords: alcohol, AUDIT, metabolic syndrome, non-communicable disease, risk of harm

Contact: Kanokporn Pinyopornpanish, M.D. Department of Family Medicine, Faculty of Medicine, Chiang Mai University, Mueang, Chiang Mai 50200, Thailand.

E-mail: knp_02@hotmail.com

. Hosting by Prince of Songkla University. All rights reserved.

This is an open access article under the CC BY-NC-ND license

(http://www.jhsmr.org/index.php/jhsmr/about/editorialPolicies\#openAccessPolicy).

J Health Sci Med Res 2021;39(2):145-155 doi: 10.31584 /jhsmr.2020771 www.jhsmr.org 


\section{Introduction}

Excessive alcohol intake is known to cause extensive health problems. According to the World Health Organization (WHO) report, about $40.0 \%$ of the world's population drinks alcohol excessively. Globally, the harmful use of alcohol has been proven to cause approximately 3.3 million deaths every year (or $5.9 \%$ of all deaths worldwide), and $5.1 \%$ of the global burden of diseases is attributable to alcohol consumption. ${ }^{1}$ Included in this, is metabolic syndrome, which is a major risk factor for non-communicable diseases (NCDs) such as hypertension (HTN), diabetes mellitus (DM), and cardiovascular diseases (CVD), which are major problems throughout the world. ${ }^{2}$

Studies regarding the association of alcohol consumption with cardiovascular risk have found that light-to-moderate alcohol consumption is significantly associated with a lower incidence of cardiovascular and all-cause mortality. J-shaped pooled curves were observed in a study's overall analysis. ${ }^{3}$ However, several other studies have reported controversial results as regards the benefits and adverse effects of drinking alcohol. ${ }^{4,5}$

As for Thailand, alcohol use is a major public health problem in all age groups ${ }^{6}$, especially in the Northern Region where, currently, the number of alcohol drinkers, including those as young as 15 years of age, is the highest in the country. ${ }^{7,8}$ Screening for alcohol problems on a primary level by using the Alcohol Use Disorders Identification Test $(\mathrm{AUDIT})^{9}$ is recommended by the $\mathrm{WHO}$ to assess the problems caused by drinking and identify the at-risk groups in order to provide proper treatment. The knowledge regarding the relationship of alcohol intake with occurrence of metabolic syndrome will help in the early prediction and planning of care for the prevention of NCDs. The current evidence of the relationship between the risk of harm and metabolic syndrome is scarce. Most studies conducted on alcohol consumption patterns have yielded controversial results. ${ }^{10}$ Therefore, the researchers were interested in studying both the quantity and the level of risk assessment by AUDIT to be utilized in the evaluation of alcohol use disorder and metabolic syndrome.

\section{Material and Methods}

A cross-sectional study was performed. The participants, who were above 18 years of age, had come to the hospital either for consultation regarding general diseases or an annual physical examination, both with and without comorbidities, and they were recruited for the study between December 2016 and January 2017 from the outpatient care setting of the Family Medicine Department, Faculty of Medicine, Chiang Mai University. The sample size was calculated based on a previous research study by Tresserra-Rimbau et al. ${ }^{11}$ using the formula of two independent proportions (two-tailed test); the number of samples in each group was 82. A research study by Lerssrimongkol ${ }^{12}$ at the outpatient clinic of the Family Medicine Department of the same hospital showed the prevalence of metabolic syndrome among healthy Thai adults to be $24.6 \%$, so the sample size required at least 333 cases. The researcher recruited a total of 400 participants. All individuals enrolled in the study signed a written informed consent before undergoing the interview, physical examination, and blood sample collection, and answering the questionnaires. All procedures were approved by the Research Ethics Committee of the Faculty of Medicine, Chiang Mai University, Thailand (No. 392/ 2559).

The data were collected from completed clinical records, and the assessments of alcohol-related problems were carried out by trained personnel. The data were divided into four parts. The first part consisted of personal data like age, sex, occupation, education, income, history of 
smoking, and amount of smoking (pack-year). The second part comprised physical examination findings such as weight (kilogram; kg) and height (centimeter; $\mathrm{cm}$ ) using a digital meter to measure and calculate the body mass index (BMI) automatically, waist circumference (WC) measured at the navel (National Institutes of Health Multiethnic Study of Atherosclerosis or NIH MESA protocol) ${ }^{13}$ using a waist tape measure, and blood pressure (BP) measured by trained staff in the sitting position after the patient had sat for at least $5 \mathrm{~min}$. The third part consisted of the blood test, which comprised fasting blood glucose (FBS), high density lipoprotein cholesterol (HDL-C), total cholesterol (TC), low density lipoprotein cholesterol (LDL-C), and triglycerides (TG) within the last 3 months to investigate for the presence of metabolic syndrome diagnostic criteria according to the American Heart Association/ National Heart, Lung, and Blood Institute Scientific Statement (AHA/NHLBI) and the International Diabetic Federation (IDF). ${ }^{14,15}$ The fourth part, the questionnaire, consisted of questions enquiring about drinking patterns ${ }^{16}$ stratified into four levels, which were abstinence (non-drinkers), occasional drinking (irregular drinkers), light-to-moderate drinking (regular drinkers who drink 10-40 gram (g)/day), and heavy drinking (regular drinkers who drink >40 g/day). The AUDIT was used as a tool in this study to assess the risk of harm from alcohol consumption, which was divided into four levels: non-drinkers, low risk (score 1-7), hazardous risk (score 8-15), and harmful use/dependence (score $>16) .{ }^{17}$ The questionnaires regarding the assessment of dietary intake and physical activity were adapted from those utilized/proposed by the National Statistical Office. ${ }^{18,19}$ (Supplementary Table 1)

All analyses were performed using STATA SE 12.1 for Windows. The descriptive data are displayed in terms of percentages. The examination of the association between alcohol consumption and metabolic syndrome indicators utilized the t-, chi-square, and ANOVA tests. Multivariate logistic regression analysis models were used to calculate the odds ratios (ORs) and the 95\% confidence intervals (Cls) for each drinking category adjusted for age, sex, smoking, and BMI. P-values $<0.05$ were considered statistically significant. Missing values were excluded from the analysis.

\section{Results}

Of the four hundred subjects, those with metabolic syndrome comprised $55.5 \%$ (222 subjects), and the data were compared between patients with and those without metabolic syndrome, as shown in Table 1. Patients with metabolic syndrome were primarily female (59.5\%), with a higher average of BMI than those without metabolic syndrome $(p$-value $<0.001)$. The other variables were not statistically significant.

Table 2 shows that the overall alcohol consumption rate was $27.3 \%$ (109 of 400 subjects), with the majority being occasional and low-risk drinkers. Younger age, male sex, and smoking were associated with increased amounts of drinking and more dangerous levels of risk of harm.

The comparison between the amount of alcohol intake and AUDIT risk level with the various factors of metabolic syndrome found the same trend in association as that between drinking patterns and AUDIT risk trends. Some metabolic syndrome indicators—waist circumference, diastolic blood pressure (dBP), and TG-were found to be associated with a greater quantity of alcohol consumption and greater risk of harm due to it ( $p$-value $0.007,<0.001$, and $<0.001$, respectively). However, the FBS association with alcohol consumption was the highest with heavy drinking and the lowest with mild-to-moderate drinking (p-value 0.004), but it did not associate with risk level (p-value 0.606). A J-shaped association was found between $\mathrm{HDL}-\mathrm{C}$ and drinking pattern; HDL-C, however, 
was found to have an inverse relationship with the risk of harm (Figure 1). The systolic BP, TC, and LDL-C were not found to be associated with either the quantity or the level of risk. Metabolic syndrome, according to the diagnostic criteria from the AHA/NHLBI and IDF, was not found to be statistically associated with drinking, with either drinking pattern or risk level.

Table 1 Demographic data of study population

\begin{tabular}{|c|c|c|c|c|}
\hline Variable & $\begin{array}{l}\text { Total } \\
(n=400)\end{array}$ & $\begin{array}{l}\text { No metabolic } \\
\text { syndrome } \\
(\mathrm{N}=178)\end{array}$ & $\begin{array}{l}\text { Metabolic } \\
\text { syndrome } \\
(\mathrm{N}=222)\end{array}$ & p-value \\
\hline Age (years), mean \pm S.D. & $61.8 \pm 10.1$ & $61.1 \pm 10.6$ & $62.4 \pm 9.7$ & 0.207 \\
\hline Female sex, n (\%) & $218(54.5)$ & $87(48.8)$ & $131(59.5)$ & 0.043 \\
\hline BMI $\left(\mathrm{kg} / \mathrm{m}^{2}\right)$, mean \pm S.D. & $25.7 \pm 4.1$ & $24.2 \pm 3.7$ & $26.8 \pm 4.0$ & $<0.001$ \\
\hline \multicolumn{5}{|l|}{ Underlying diseases } \\
\hline No underlying disease & $28(7.0)$ & $24(13.5)$ & $4(1.8)$ & $<0.001$ \\
\hline Diabetes mellitus & $89(22.2)$ & $14(7.9)$ & $75(33.8)$ & $<0.001$ \\
\hline Hypertension & $265(66.2)$ & $97(54.5)$ & $168(75.7)$ & $<0.001$ \\
\hline Dyslipidemia & $225(56.2)$ & $69(38.8)$ & $156(70.3)$ & $<0.001$ \\
\hline Other & $72(18.0)$ & $37(20.8)$ & $35(15.8)$ & 0.194 \\
\hline Living in an urban area, $\mathrm{n}(\%)$ & $182(45.5)$ & $87(48.88)$ & $95(42.8)$ & 0.225 \\
\hline Smoking, $\mathrm{n}(\%)$ & $79(19.7)$ & $39(22.4)$ & $39(17.5)$ & 0.221 \\
\hline Pack-year among smokers, mean \pm S.D. & $12.1 \pm 10.8$ & $13.4 \pm 11.8$ & $10.9 \pm 9.7$ & 0.302 \\
\hline Higher education, n (\%) & $143(35.7)$ & $62(34.8)$ & $81(36.5)$ & 0.731 \\
\hline Drinkers, n (\%) & $109(27.2)$ & $50(28.1)$ & $59(26.6)$ & 0.735 \\
\hline Standard drink (drink/day) among drinkers, mean \pm S.D. & $4.3 \pm 3.2$ & $4.34 \pm 2.8$ & $4.3 \pm 3.4$ & 0.926 \\
\hline Income, n (\%) & & & & 0.562 \\
\hline$<10,000 \mathrm{baht} / \mathrm{month}$ & $162(40.5)$ & $76(42.7)$ & $86(37.7)$ & \\
\hline $10,000-30,000$ baht/month & $160(40.0)$ & $66(37.1)$ & $94(42.3)$ & \\
\hline$>30,000 \mathrm{baht} / \mathrm{month}$ & $78(19.5)$ & $36(20.2)$ & $42(18.9)$ & \\
\hline \multicolumn{5}{|l|}{ Dietary intake } \\
\hline Cooking oil frequently, n (\%) & $95(23.7)$ & $44(24.7)$ & $51(23.0)$ & 0.683 \\
\hline Protein and protein products, >4 day/wk, n (\%) & $237(59.2)$ & $109(61.2)$ & $128(57.6)$ & 0.469 \\
\hline High fat food, $>4$ day/wk, n (\%) & $42(10.5)$ & $22(12.4)$ & $20(9.0)$ & 0.277 \\
\hline Snacks, >4 day/wk, n (\%) & $11(2.7)$ & $4(2.2)$ & $7(3.1)$ & 0.582 \\
\hline Fast food, $>4$ day/wk, n (\%) & $2(0.5)$ & $0(0.0)$ & $2(0.9)$ & 0.204 \\
\hline Fruits and vegetables, >4 day/wk, n (\%) & $348(87.0)$ & $158(88.7)$ & $190(85.6)$ & 0.348 \\
\hline Sweets, >4 day/wk, n (\%) & $164(41.0)$ & $72(40.4)$ & $92(41.4)$ & 0.841 \\
\hline \multicolumn{5}{|l|}{ Physical activity } \\
\hline No exercise, n (\%) & $197(49.2)$ & $85(47.7)$ & $112(50.4)$ & 0.592 \\
\hline Housework, n (\%) & & & & 0.685 \\
\hline$\leq 2$ times/wk & $96(24.0)$ & $44(24.7)$ & $52(23.4)$ & \\
\hline 3-4 times/wk & $37(9.2)$ & $14(7.9)$ & $23(10.3)$ & \\
\hline Nearly everyday - everyday & $267(66.7)$ & $120(67.4)$ & $147(66.2)$ & \\
\hline Sedentary lifestyle (hr/day), mean \pm S.D. & $6.8 \pm 2.2$ & $6.7 \pm 2.2$ & $6.9 \pm 2.3$ & 0.200 \\
\hline
\end{tabular}

S.D.=standard deviation, $\mathrm{BMl}=$ body mass index, $\mathrm{wk}=$ week, $\mathrm{hr}=\mathrm{hour}, \mathrm{kg} / \mathrm{m}^{2}=\mathrm{kilogram} /$ square meters 


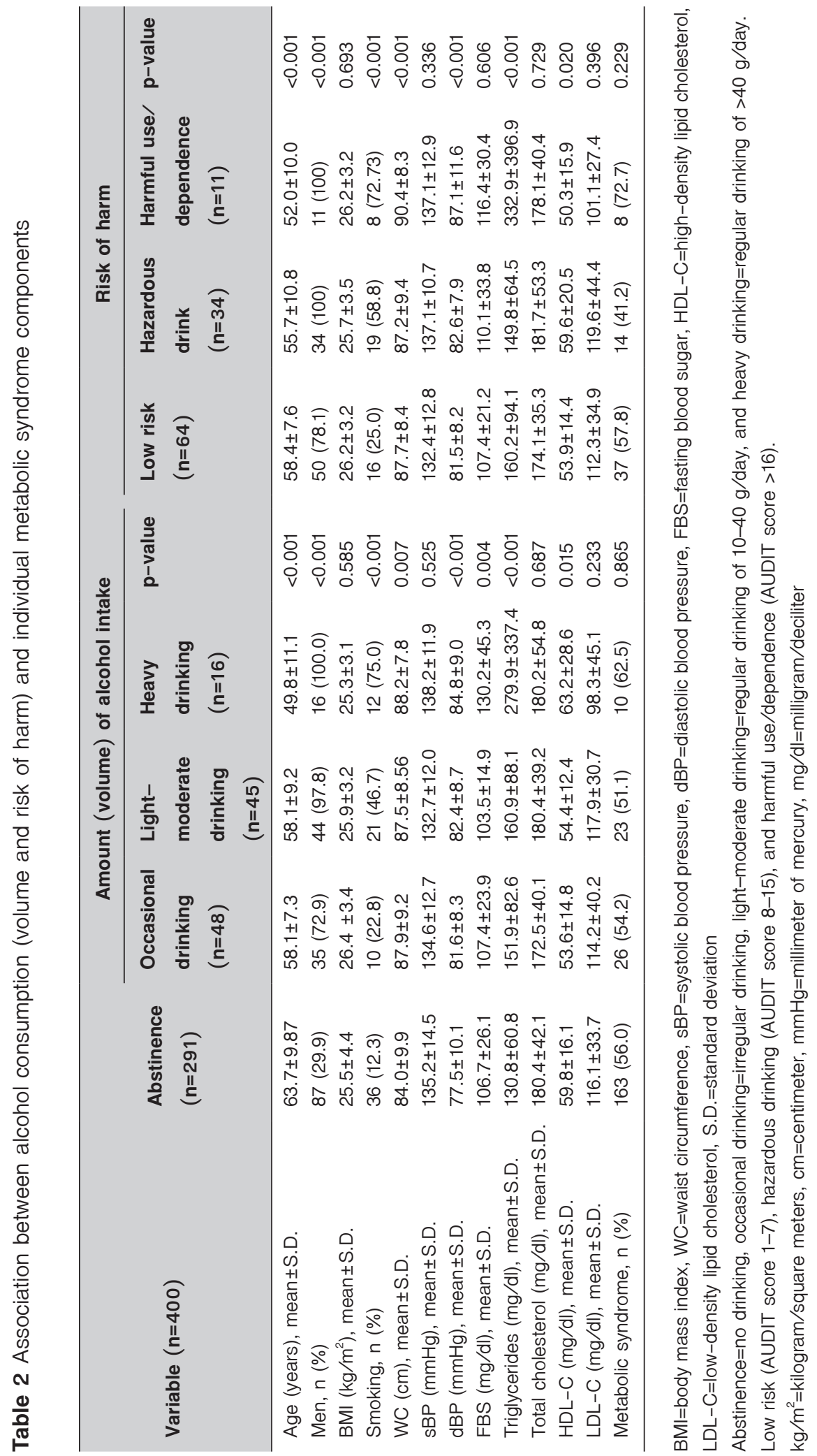



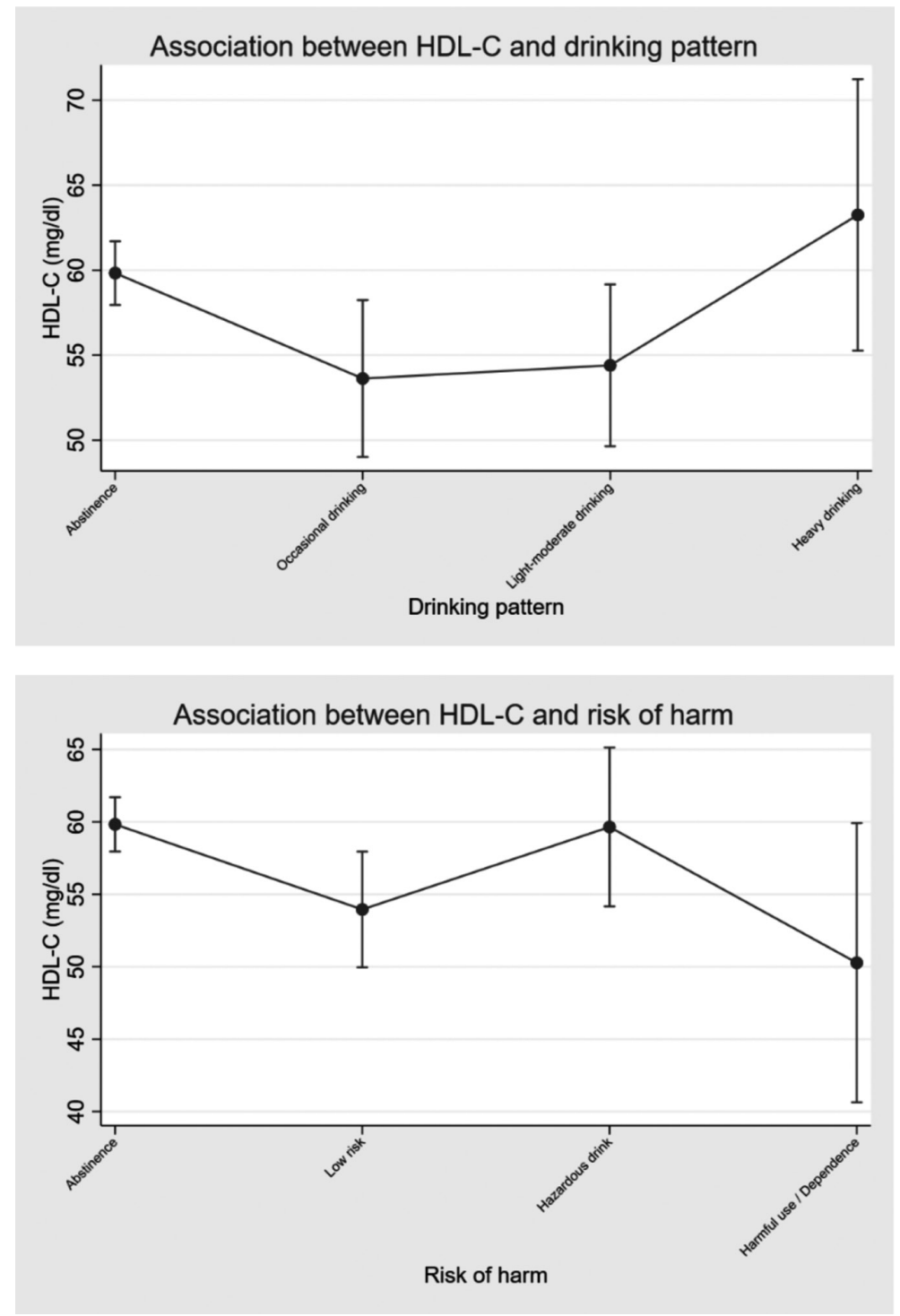

HDL-C=high density lipoprotein cholesterol, mg/dl=milligram/deciliter

Figure 1 Association between high density lipoprotein cholesterol and alcohol drinking

The results of the multivariate analysis using a logistic regression model and adjusted odds ratios for age, sex, smoking, and BMI are shown in Table 3. The ratios comparing non-drinkers with metabolic syndrome were significantly increased in the heavy drinker $(\mathrm{OR}=4.4$, 95\% confidence interval (Cl) 1.2-15.6, p-value 0.021) and harmful use/dependent categories $(\mathrm{OR}=5.0,95 \% \mathrm{Cl}$ 1.1-23.1, p-value 0.039). 
Table 3 Association between metabolic syndrome and alcohol consumption analyzed via logistic regression analysis

\begin{tabular}{|c|c|c|c|}
\hline Alcohol consumption & $\begin{array}{l}\text { Adjusted } \\
\text { odds } \\
\text { ratio* }\end{array}$ & $95 \% \mathrm{Cl}$ & p-value \\
\hline \multicolumn{4}{|l|}{ Amount of alcohol intake } \\
\hline Non-drinker & 1.0 & & \\
\hline Occasional drinker & 1.2 & $0.6-2.6$ & 0.555 \\
\hline Light-moderate drinker & 1.5 & $0.7-3.2$ & 0.342 \\
\hline Heavy drinker & 4.4 & $1.2-15.6$ & 0.021 \\
\hline \multicolumn{4}{|l|}{ AUDIT risk score } \\
\hline Abstinence & 1.0 & & \\
\hline Low risk & 1.5 & $0.8-2.9$ & 0.220 \\
\hline Hazardous drinking & 1.0 & $0.4-2.6$ & 0.925 \\
\hline Harmful use/dependence & 5.0 & $1.1-23.1$ & 0.039 \\
\hline
\end{tabular}

$\mathrm{Cl}=$ confidence interval

*adjusted for age, sex, smoking, and BMI

\section{Discussion}

This study found the prevalence of current drinking behavior of $27.3 \%$ to be primarily about occasional and low-risk drinking. Based on the assessment of both the quantity of alcohol and the level of risk from alcohol drinking, their association with metabolic indicators was in the same direction; an exception was $\mathrm{HDL}-\mathrm{C}$, which had a J-shaped association with the amount of alcohol intake but an inverse association with risk level. The prevalence of metabolic syndrome was increased among heavy and harmful use/dependent drinkers.

The current alcohol drinking ratio found by this study was $27.3 \%$, which is higher than that of the total world population (22.6\%). ${ }^{1}$ However, this is slightly lower than that of the Thai population. A situational report of alcohol consumption in $2017^{19}$ found that $28.4 \%$ of the country's population are drinkers. The drinkers tended to be male and young; as a matter of fact, drinking in greater quantities was found to be associated with younger ages ${ }^{17}$, a finding that is similar to the findings of various studies conducted in several countries. ${ }^{20-23}$

The association between alcohol consumption and the components of metabolic syndrome was found to have both negative and positive effects. The negative impacts on health included an increase in the risk for having high blood sugar and TG levels as well as a larger WC due to belly fat. This is consistent with the findings of previous studies, which have reported that heavy drinking is associated with an increased risk of diabetes, dyslipidemia, and metabolic syndrome among liquor consumers. ${ }^{24}$ This can be explained by the fact that alcohol can increase blood sugar levels and calory intake. Caton et al. reported the effect of high-dose alcohol (4 units) on stimulating appetite and increasing food intake, thus alcohol may contribute to a positive energy balance via its additive effects to the total energy intake. ${ }^{25}$ The excess energy in the body is transformed into TG, resulting in higher levels of serum TG. ${ }^{26}$ The accumulation of excessive fat increases waist circumference and body weight. $^{27}$ Nevertheless, some studies have reported that the moderate consumption of alcohol accounts for an energy balance equation minimizing weight gain due to heat generation from thermogenesis ${ }^{28}$; however, this was not observed in this study.

Moreover, alcohol consumption is associated with an elevated $\mathrm{BP}^{29}$ In this study, an association with only $\mathrm{dBP}$ level was found, and it was higher. This is rather surprising as, in general, alcohol can cause high BP as regards both SBP and $\mathrm{dBP}$. This could be explained by several mechanisms such as enhanced sympathetic activity, stimulation of the renin-angio-tensin-aldosterone system, increased cortisol levels, increased vascular reactivity, oxidative injury, and the inhibition of nitric oxide production without time dependency. ${ }^{30,31}$ However, a previous study found that alcohol consumption increases both $\mathrm{sBP}$ and $\mathrm{dBP}$, but only $\mathrm{dBP}$ values increase 
enough to be clinically significant. ${ }^{32}$ This may also be explained by the fact that heavy drinkers tend to carry an increased risk of high $\mathrm{dBP}$, and they are mostly male, with sedentary lifestyles, who also engage in heavy smoking. ${ }^{33,34}$

In addition, the authors found that alcohol could have a positive effect on health by elevating serum HDL-C levels via raising the transport rates of the major HDL apolipoproteins apoA-I and $-1 .^{35,36}$ However, it is not recommended to use alcohol as a means to increase the level of HDL-C. ${ }^{37}$ Long-term drinking has been found to be associated with lower HDL-C concentrations. ${ }^{38}$ This would explain why HDL-C was inversely related to the risk of harm compared to its relationship with the amount of alcohol intake. Most questions in AUDIT pertain to the time spent consuming alcohol, the estimated duration of this risk behavior, and self-perception as regards one's drinking habit. Drinkers who reported to have high risk of harm could be associated with a longer duration of exposure to alcohol, which may result in liver injury and interference with cholesterol synthesis. ${ }^{39}$

Apart from HDL-C, there were other metabolic syndrome biomarkers that were associated with the level of risk in the same manner as the amount of consumption. The reason for this might be that people who drink large quantities of alcohol are often assessed as having a higher risk of harm. The AUDIT questionnaire consists of questions enquiring about the amount of alcohol, and if the answer is "high amounts," then the risk will be considered as "increased." In addition, those who drink large amounts of alcohol are more likely to have health problems or social consequences, which may influence their perception of incurring a higher level of harm. ${ }^{37}$

The strength of the present study is the utilization of risk assessment obtained via the AUDIT questionnaire to study its association with metabolic syndrome, which, to the authors' knowledge, has not yet been studied in
Thailand. However, the study has some limitations. Firstly, most participants suffered from chronic diseases, which may not be a fair representation of the characteristics of the general population. Secondly, as mentioned in the discussion section, using the AUDIT risk assessment to compare to the quantity of alcohol consumption might confound the interpretation of the data as one question in AUDIT aims to assess the amount of drink. Accordingly, the results could be similar. Future studies need to consider using other risk assessment questionnaires, the results for which may be different. Lastly, as the measurement of WC used in this study is different from the more commonly used method recommended by $\mathrm{WHO}$, this could have possibly led to an underestimation of the prevalence of metabolic syndrome. However, even when using these two different measures, similar patterns of association between cardiometabolic risks and WC have been reported. ${ }^{40}$

\section{Conclusion}

Alcohol drinking tends to be associated with an increased risk of metabolic syndrome, especially when heavy drinking (in excess of $40 \mathrm{~g} /$ day) is involved and among patients who check positive for harmful use or alcohol dependency in level of risk. Offering advice to help patients restrict their drinking habits can be beneficial in the attempt to reduce the incidence of metabolic syndrome. At the same time, people who drink alcohol, especially heavy drinkers and those who are at high risk of harm, should be assessed for metabolic problems in order to prevent further complications due to this condition.

\section{Funding sources}

This research was supported by a grant from Faculty of Medicine, Chiang Mai University (No. 0522560). 


\section{Conflict of interest}

None to declare

\section{References}

1. World Health Organization. Global status report on alcohol and health 2014 [monograph on the Internet]. Geneva: WHO; 2014 [cited 2018 Jun 8]. Available from: https://apps.who. int/iris/bitstream/handle/10665/112736/9789240692763_ eng.pdf;jsessionid=88838C3179E9CA89F0BC7FEF9C559FDB? sequence $=1$

2. World Health Organization. Global Status Report on Alcoho and Health 2011 [monograph on the Internet]. Geneva: WHO; 2011 [cited 2018 Jun 8]. Available from: https://apps.who. int/iris/bitstream/handle/10665/44499/9789241564151_ eng.pdf?sequence $=1$

3. Costanzo S, Di Castelnuovo A, Donati MB, lacoviello L, de Gaetano G. Alcohol consumption and mortality in patients with cardiovascular disease: a meta-analysis. J Am Coll Cardiol 2010;55:1339-47.

4. Di Castelnuovo A, Costanzo S, Bagnardi V, Donati MB, lacoviello L, de Gaetano G. Alcohol dosing and total mortality in men and women: an updated meta-analysis of 34 prospective studies. Arch of Intern Med. 2006;166:2437-45.

5. Di Castelnuovo A, Rotondo S, lacoviello L, Donati MB, De Gaetano G. Meta-analysis of wine and beer consumption in relation to vascular risk. Circulation 2002;105:2836-44.

6. Thamarangsi T. The situation of alcohol consumption and its' impacts in Thailand in B.E. 2556. Nonthaburi: The Graphico System; 2013.

7. Lekfueng N, Tharnpanich N, Tacharoen K, Wongwaisiriwatana $\mathrm{S}$, Witworapong $\mathrm{N}$. The situation of alcohol consumption in Northern Thailand 2015: Research Center for alcohol problems. Bangkok: Duen Tula Publishing House; 2015.

8. Chaisong S, Pakdeesettakul K, Thammarangsee T. Provincial alcohol report 2011. Nonthaburi: The Graphico System Publishing; 2013.

9. Babor T, Higgins-Biddle J, Saunders J, Monteriro M. The Alcohol Use Disorders Identification Test: guidelines for use in primary care. $2^{\text {nd }}$ ed. Geneva: WHO; 2001.

10. Sun K, Ren M, Liu D, Wang C, Yang C, Yan L. Alcohol consumption and risk of metabolic syndrome: a metaanalysis of prospective studies. Clin Nutr 2014;33:596-602.
11. Tresserra-Rimbau A, Medina-Remón A, Lamuela-Raventós RM, Bulló M, Salas-Salvadó J, Corella D, et al. Moderate red wine consumption is associated with a lower prevalence of the metabolic syndrome in the PREDIMED population. $\mathrm{Br} J$ Nutr 2015;113(Suppl 2):S121-30.

12. Lerssrimongkol C, Angkurawaranon C, Thongtong P, Promkumton P, Kusirisin W. Prevalence of metabolic syndrome among healthy Thai adults at the Out-Patient Clinic of Family Medicine Department. Lanna Public Health J 2008;4:392-8.

13. World Health Organisation. Waist circumference and waisthip ratio: report of a $\mathrm{WHO}$ expert consultation [monograph on the Internet]. Geneva: WHO; 2011 [cited 2016 Jun 22]. Available from: https://www.who.int/publications///item/ 9789241501491

14. Lam DW, LeRoith D. Metabolic syndrome [monograph on the Internet]. South Dartmouth (MA): MDText.com, Inc.; 2000 [cited 2019 Feb 11]. Available from: https://www.ncbi. nlm.nih.gov/books/NBK278936/

15. Grundy SM, Cleeman JI, Daniels SR, Donato KA, Eckel RH, Franklin BA, et al. Diagnosis and management of the metabolic syndrome. AHAMHLBI Scientific Statement. Circulation 2005;112:2735-45.

16. Thaikla K. Thai Standard Drinks Calculator version 1.0: Research Center for alcohol problems. Chiang Mai: Institute of Health Sciences, Chiang Mai University; 2010 [cited 2019 Feb 11]. Available from: https://nsbapp.com/dwbb/ ThaiDrink/

17. Wakabayashi M, McKetin R, Banwell C, Yiengprugsawan V, Kelly M, Seubsman SA, et al. Alcohol consumption patterns in Thailand and their relationship with non-communicable disease. BMC Public Health 2015;15:1297.

18. National Statistical Office Thailand. Executive Summary: The 2017 Survey on Health, Welfare, and food consumption behavior [monograph on the Internet]. Bangkok: National Statistical Office Thailand; 2017 [cited 2018 Nov 8]. Available from: http://www.nso.go.th/sites/2014

19. National Statistical Office Thailand. The smoking and drinking behavior survey 2017 [monograph on the Internet]. Bangkok: National Statistical Office Thailand; 2017 [cited 2020 Jun 6]. Available form: http://www.nso.go.th/sites/2014en/ Survey/social/health/SmokingDrinking/2017/Full\%20Report. pdf 
20. Bermudez V, Martinez MS, Chavez-Castillo M, Olivar LC, Morillo J, Mejias JC, et al. Relationship between alcohol consumption and components of the metabolic syndrome in adult population from Maracaibo City, Venezuela. Adv Prev Med 2015:352547.

21. Jin L, Huang $Y, B i ~ Y$, Zhao L, Xu M, Xu Y, et al. Association between alcohol consumption and metabolic syndrome in 19,215 middle-aged and elderly Chinese. Diabetes Res Clin Pract 2011;92:386-92.

22. Kabagambe EK, Baylin A, Ruiz-Narvaez E, Rimm EB, Campos $\mathrm{H}$. Alcohol intake, drinking patterns, and risk of nonfatal acute myocardial infarction in Costa Rica. Am J Clin Nutr 2005;82:1336-45.

23. Lee MY, Kim MY, Kim SY, Kim JH, Kim BH, Shin JY, et al. Association between alcohol intake amount and prevalence of metabolic syndrome in Korean rural male population. Diabetes Res Clin Pract 2010;88:196-202.

24. Baik I, Shin C. Prospective study of alcohol consumption and metabolic syndrome. Am J Clin Nutr 2008;87:1455-63.

25. Caton SJ, Ball M, Ahern A, Hetherington MM. Dose-dependent effects of alcohol on appetite and food intake. Physiol Behav 2004;81:51-8.

26. Klop B, do Rego AT, Cabezas MC. Alcohol and plasma triglycerides. Curr Opin Lipidol 2013;24:321-6.

27. Traversy G, Chaput JP. Alcohol consumption and obesity: an update. Current Obesity Reports 2015;4:122-30.

28. Suter PM. Is alcohol consumption a risk factor for weight gain and obesity?. Crit Rev Clin Lab Sci 2005;42:197-227.

29. Fan AZ, Russell M, Dorn J, Freudenheim JL, Nochajski T, Hovey $\mathrm{K}$, et al. Lifetime alcohol drinking pattern is related to the prevalence of metabolic syndrome. The Western New York Health Study (WNYHS). Eur J Epidemiol 2006;21:129-38.

30. Husain K, Ansari RA, Ferder L. Alcohol-induced hypertension: Mechanism and prevention. World J Cardiol 2014;6:245-52.

31. Moreira LB, Fuchs FD, Moraes RS, Bredemeier M, Duncan
BB. Alcohol intake and blood pressure: the importance of time elapsed since last drink. J Hypertens 1998;16:175-80.

32. Seppa K, Laippala P, Sillanaukee P. High diastolic blood pressure: common among women who are heavy drinkers. Alcohol Clin Exp Res 1996;20:47-51.

33. Dong-Qing Z, Chang-Quan H, Yan-Ling Z, Bi-Rong D, Qing-Xiu L. Cigarette smoking is associated with increased diastolic blood pressure among Chinese nonagenarians/ centenarians. Blood Press 2014;23:168-73.

34. Midha T, Lalchandani A, Nath B, Kumari R, Pandey U. Prevalence of isolated diastolic hypertension and associated risk factors among adults in Kanpur, India. Indian Heart J 2012; 64:374-9

35. De Oliveira ESER, Foster D, McGee Harper M, Seidman CE, Smith JD, Breslow JL, et al. Alcohol consumption raises HDL cholesterol levels by increasing the transport rate of apolipoproteins A-I and A-II. Circulation 2000;102:2347-52.

36. Kralova Lesna I, Suchanek P, Stavek P, Poledne R. May alcohol-induced increase of HDL be considered as atheroprotective?. Physiol Res 2010;59:407-13.

37. Galan I, Valencia-Martin JL, Guallar-Castillon P, RodriguezArtalejo F. Alcohol drinking patterns and biomarkers of coronary risk in the Spanish population. Nutr Metab Cardiovasc Dis 2014;24:189-97.

38. Huang S, Li J, Shearer GC, Lichtenstein AH, Zheng X, Wu Y, et al. Longitudinal study of alcohol consumption and HDL concentrations: a community-based study. Am J Clin Nutr 2017; 105:905-12

39. Okamoto Y, Fujimori Y, Nakano H, Tsujii T. Role of the liver in alcohol-induced alteration of high-density lipoprotein metabolism. J Lab Clin Med 1988;111:482-5.

40. Ross R, Berentzen T, Bradshaw AJ, Janssen I, Kahn HS, Katzmarzyk PT, et al. Does the relationship between waist circumference, morbidity and mortality depend on measurement protocol for waist circumference?. Obes Rev 2008;9:312-25. 
Supplementary Table 1 Example of the questionnaire for assessing dietary intake and physical activity adapted from the National Statistical Office

Diet

Which cooking method do you usually use? (choose only one)
$\square$ (1) boiling
(5) half-cooking
$\square$ (2) stewing
$\square$ (6) toasting/grilling
$\square$ (3) stir-frying
$\square$ (7) baking
$\square$ (4) frying
$\square$ (8) other

\begin{tabular}{|l|l|l|l|l|l|}
\hline $\begin{array}{l}\text { During the past month, how many days } \\
\text { per week did you eat ... }\end{array}$ & Never & 1-2 days/week & 3-4 days/week & 5-6 days/week & Everyday \\
\hline 1. Meat or processed meat & & & & & \\
\hline 2. High-fat food & & & & & \\
\hline 3. Snacks & & & & & \\
\hline 4. Junk food & & & & & \\
\hline 5. Fruit and vegetable & & & & & \\
\hline 6. Sweet drinks/energy drinks & & & & & \\
\hline
\end{tabular}

\section{Physical activity}

\begin{tabular}{|l|l|}
\hline On average, how many days per week do you ... & Frequency (days/week) \\
\hline A. Have vigorous activity/exercise? (at least 20 minutes continuously) & \\
\hline B. Have moderate activity/exercise (at least 20 minutes continuously) & \\
\hline C. Have light activity (at least 20 minutes continuously) & \\
\hline D. Walk non-stop for at least 10 minutes & \\
\hline How often do you do housework or gardening? & $\square$ Never/rarely \\
& $\square \leq 2$ times/week \\
& $\square$ 3-4 times/week \\
& $\square$ Nearly everyday/everyday \\
\hline How many hours per day do you ... & Duration (hours/day) \\
\hline A. Sleep during daytime & \\
\hline B. Watch television or use the computer & \\
\hline C. Sit (in all situations) & \\
\hline
\end{tabular}

